Research Article

\title{
Injury Related to Fall and Its Predictors among Medically Diagnosed Adults with Visual Impairment in Ethiopia: An Observational Cross-Sectional Study
}

\author{
Moges Gashaw ${ }^{1}{ }^{1}$ and Biruk Adie Admass ${ }^{2}$ \\ ${ }^{1}$ Department of Physiotherapy, School of Medicine, College of Medicine and Health Sciences, \\ University of Gondar Comprehensive Specialized Hospital, Gondar, Ethiopia \\ ${ }^{2}$ Department of Anesthesia, School of Medicine, College of Medicine and Health Sciences, \\ University of Gondar Comprehensive Specialized Hospital, Gondar, Ethiopia \\ Correspondence should be addressed to Moges Gashaw; mogesgashaw1@gmail.com
}

Received 24 October 2020; Revised 8 February 2021; Accepted 16 February 2021; Published 27 February 2021

Academic Editor: Paulo Adriano Schwingel

Copyright ( $) 2021$ Moges Gashaw and Biruk Adie Admass. This is an open access article distributed under the Creative Commons Attribution License, which permits unrestricted use, distribution, and reproduction in any medium, provided the original work is properly cited.

\begin{abstract}
Background. Fall-related injury is the common cause of unintentional injury and premature death among people with visual impairment. So far, the knowledge about fall-related injuries among medically diagnosed visual impairment people living in lowand middle-income countries is scarce. Hence, this study is a preliminary attempt to assess the fall-related injury and its determinants among adult people with medically diagnosed visual impairment individuals. Methods. An institutional-based crosssectional study was conducted from March to July 2018 with a total sample size of 337 study participants. The study participants were recruited by using a systematic random sampling method. Univariable and multivariable binary logistic regression model analysis was used to identify predictors of fall-related injuries with IBM Statistical Package for Social Sciences version 23. Results. A total of 320 adults with visual impairments participants have participated in this study. The finding of this study was reported as follows: $24.7 \%$ of (95\% CI: 20.0-29.4\%) adults with visual impairments experienced one or more fall-related injuries. The main predictors of fall-related injuries identified by multivariate analysis were severity of visual impairment: moderate (AOR, 2.91; 95\% CI: 1.23 - 6.87), severe (AOR, 3.58; 95\% CI: 1.26-10.17), cause of visual impairment: cataract (AOR, 10.63; 95\% CI: 2.49 - 45.26), diabetic retinopathy (AOR, 15.35; 95\% CI: 2.51-93.96), taking medication (AOR, 6.35; 95\% CI: 2.93-13.75), having family support (AOR, 2.13; 95\% CI: 1.08 - 4.19), and depression (AOR 3.82, 95\% CI: 1.27-11.45). Conclusion. Soft tissue injuries were the most common fall-related injuries reported by the study participants. The severity of visual impairment, the cause of visual impairment, taking one or more medication, having family support, and having depression were significant predictors of fall-related injuries.
\end{abstract}

\section{Introduction}

Visual impairments (VI) have an extreme impact on the physical, psychological, and socioeconomically development of individuals and societies [1]. Visual impairment is more prevalent in low- and middle-income countries (LMICs); about $80 \%-90 \%$ of the world's visually impaired people live in LMICs [2]. In Sub-Saharan African countries, including Ethiopia, visual impairment occurred on average for 70 million people. Visual impairment is reported to be an independent risk factor for fall-related injuries and fall-related death among older adults [3].

Falls are one of the most common leading causes of unintentional fall-related injury and a cause of premature death among people with visual impairment [4]. A fall is defined as an event which results in a person coming to rest inadvertently on the ground or floor or other lower level with/without fall-related injury [5]. Fall-related injury is the common cause of unintentional injury and premature death among people with visual impairment. In all regions of the 
world, fall-related death rates are the highest among people with visual impairment and adults over the age of 50 years $[6,7]$.

Falls can lead to moderate to severe injuries, fear of falling, loss of independence, and death. In 2012, the direct cost of falls adjusted for inflation was $\$ 30$ billion; by 2020 , the annual direct and indirect cost of fall-related injuries is expected to be doubled. Fall-related trauma accounted for $5.3 \%$ of all hospitalization of adults with high hospital charges [8]. Falls were the most common event with $54 \%$ of the participants with VI reporting at least one fall and $30 \%$ reported more fall and got fall-related injuries [9]. The prevalence of self-reported falls among people with visual impairment in Ethiopia was 26.8\% [10].

The most common factors that may influence fall-related injuries and fall are age, sex, the severity of visual impairment, body mass index, psychosocial, physical environment, depression, decreased vestibular reflexes, decreased muscle strength, increasing postural sway, concurrent medical issues, fear of fall, and preexisting medical comorbidities directly increasing the incidence of falls [11-13].

Older adults with VI have one of the highest injuryrelated morbidity and mortality rates and have a poor prognosis and more complications after fall-related injuries, which have significant ramifications for associated health care costs. It has been demonstrated that the risk of unintentional injuries resulting from falls is higher for individuals with VI compared with those with normal vision [14]. Though, studies reported the burden of falls in different populations. So far, the knowledge about fall-related injuries among medically diagnosed VI people living in LMICs is scarce. Hence, this study is a preliminary attempt to assess the fall-related injury and its determinants among adult people with medically diagnosed visual impairment individuals. Thus, this evidence will help us to establish preventive measures among this population.

\section{Methods}

2.1. Study Design, Setting, and Participants. An institutionalbased cross-sectional study was conducted from March to July 2019 among adults with medically diagnosed visual impairment during the study period. This eye care center provides all-inclusive clinical and community eye health services for twelve zones and serves as a major referral center for more than 14 million people living in and around the region, North West Ethiopia. It is estimated that a minimum of 5000 patients utilize different eye care services per year and this is the only clinical catchment area for visually impaired individuals in Gondar city, situated in the northern part of Ethiopia. Based on the 2016 population estimates of Gondar city administration bureau, Gondar had a total population of 335,000 with $3200 / \mathrm{km}^{2}$, with an estimated total household count of 53725 and 182000 (52\%) women [15].

The study area is geographically a challenging mountainous landscape and unsafe sometimes even for normalsighted people and perilous for liable people like older people, physically challenged people, and people with visual impairment. The study setting of the ophthalmic outpatient clinic receives a wide range of ambulatory VI patients, visiting for consultation, medication, eye-glasses, mobility aids, and surgery appointments, and the study setting is the only referral hospital for the entire Gondar region. Consequently, individuals with a wide spectrum of visual impairment visit this institution. As of 2017, the ophthalmic clinic cares for 40 to 60 visually impaired patients every day. So, an average of 1500 adult participants is likely to visit the clinic during the six weeks data collection period. Adults with visual impairment, who can walk independently with or without mobility aids and aged $\geq 18$ years with no other hearing disability, were included in this study. However, adults with visual impairment who ambulate dependently in personal support and have a hearing impairment, which cannot communicate verbally and in writing, were excluded from the study.

\subsection{Sample Size Determination and Sampling Procedure.} The sample size required for this study was determined using the single population proportion formula [16] and calculated using the Epi Info software version 7.0 (Centres for Disease Control and Prevention, USA). The samples were obtained from a relatively small population $(N=1500)$.

The following assumptions were used to determine the required sample: prevalence of $50 \%$ since no past regional data exists, a confidence level of 95, 5\% margin of error, and $5 \%$ margin of error. So, the sample was taken from a relatively small population $(N=1500)$, and the required sample size was obtained by the following calculation:

$$
n=\frac{(z a / 2) 2 p(1-p)}{d^{2}}
$$

where $n=$ sample size, $Z=95 \%$ confidence limit (1.96), $p=$ proportion of the population which take $50 \%, d=$ margin of error or degree of accuracy desired (0.05), and $n=(1.96) 2 \mathrm{x}$ (0.5) $(0.5) /(0.05)^{2}=385$; since the sample were taken from a relatively small population, correction formula was used:

$$
\begin{aligned}
& n=\frac{n}{1}+\frac{n}{N} \\
& n=\frac{385}{1}+\frac{385}{1500}=\frac{385}{1.256}=306 .
\end{aligned}
$$

The derived power calculated sample size was $n=306$. Accounting for an estimated refusal or nonresponse rate of $10 \%$, the final sample size was calculated to be $n=337$.

The study participants were recruited by using a systematic random sampling method by arranging the patients based on their chart number from the registered engagement register selected in Kth interval each day during the study period. The first participant between 1 and $\mathrm{K}$ was selected randomly by a lottery method, and the next participant was interviewed every fourth interval. The route was continual until the sketchy eligible sample size was reached.

The operational definition of the variables: fall-related injury is any injury that results from a fall after diagnosis of vision problem. Did you have any injury as a result of a fall 
after knowing you are with a vision problem? (Yes/No). Visual impairment (in any eye): which could not be eliminated by refractive correction or lenses (noncorrectable); significant loss of vision on which Snellen's chart reading is less than $6 / 12$ to no light perception; mild visual impairment, presenting with a visual acuity of less than 6/12(20/40) greater than or equal to $6 / 18(20 / 60)$; moderate visual impairment, presenting with visual acuity of less than $6 / 18(20 /$ 60 ) to greater than or equal to 6/60(20/200); and severe visual impairment, presenting with visual acuity of less than $6 / 60(20 / 200)$ to no light perception [17].

Physical activity was categorized as "Yes" or "No" based on the response to three questions: (1) Do you exercise regularly now? (2) If you exercise regularly, how many days a week do you exercise? (3) If you exercise regularly, how many minutes a day, on average, do you exercise? For question number 1 , the response alternatives were "Yes" or "No" and for question no 2, the respondent has to fill the number of days/week, and for question no 3, the respondent has to fill the average minutes of exercising per day.

2.3. Study Procedures. After providing a verbal account and explaining about this study to the caregivers and the study participants, all study subjects signed the written informed consent statement. A structured data collection questionnaire (Additional File 1) was developed based on an allembracing review of different literature [18-21]. The questionnaire was initially prepared in English and then translated into Amharic to the local language and back into English to check the consistency of the questions and corrections were made accordingly.

The questionnaire included domains like sociodemographic characteristics, behavioral characteristics, physical measurements, visual related characteristics, medical comorbidity, and fall-related characteristics. In addition, the medical charts of the participants were reviewed to extract additional information like the diagnosis of medical comorbidity, the type of medication the participants took, and the diagnosis of VI. Most of the study participants took antidepressant, antihypertensive medication for cardiovascular conditions and medication to control diabetes mellitus. The questionnaires were orally administered to each patient individually during an interview with four trained ophthalmic nurses and the responses of the patient were recorded in the data collection sheet. Factors related to visual impairment, visual acuity measurement, Snellen's E-chart measurement, and medical eye screening reports evaluated by an optometrist on the day of data collection were recorded by the data collector. Counterchecking of the daily filled questionnaire and regular supervision were done by MG and BA. To minimize the possible response bias, the questions were read aloud in a quiet ambiance following which the participants were told to repeat the question to assure reception of the question clearly. Care was taken by data collectors to simplify the questions as much as possible, accompany caregivers during self-reporting and explanations were given whenever question arose.
2.4. Statistics and Data Analysis. Data were entered using Epi-Info software version 7.1 and exported to the IBM Statistical Package for Social Sciences (SPSS) version 23 for the window for further analysis and for coding, recoding, storing, and further analysis. Descriptive statistics like frequencies, percentages, means, and standard deviations were used for all participant characteristics and factors associated with fall-related injuries. With fall-related injuries (categorized as Yes versus No) as a dependent variable, logistic regression analysis was done to determine the association with different independent variables.

Independent variables included in the regression models were sociodemographic characteristics (age, gender, residence, marital status, level of education, occupation, and income); physical measurements (height, weight, and BMI); behavioral factors (alcohol drink, smoking, and physical exercise); vision-related factors (mild vision impairment, moderate vision impairment, and severe vision impairment); and the current level of mobility, comorbidity, and drug intake. Multiple regression and interaction terms were employed to examine the potential association. Variables were entered into the model using forced entry and categories were used as covariates for detailed analyses. Results were considered statistically significant with $95 \%$ confidence intervals not containing unity (equal to $P$ value $<0.05$ ) for both the main effects and interaction terms.

Initially, bivariate analysis was conducted and independent variables that were found statistically significant were fitted into the multivariate model using the backward stepwise (likelihood ratio) method. We tested for potential statistically significant interactions by adding the product of the covariates in the multivariable-adjusted logistic regression models. Crude and adjusted odds ratios and 95\% confidence intervals were calculated from univariate and multivariate logistic models for associations between the independent variables and the dependent variable. Variables were entered into the model using forced entry and categories were used as covariates for detailed analyses. Results were considered statistically significant with $95 \%$ confidence intervals not containing unity $(P$ value $<0.05)$ for both the main effects and interaction terms.

When clear subgroups seemed to be present in the dataset, significance testing (Pearson $\chi 2$ ) and, if appropriately sized subgroups per category remained, logistic regression analyses were conducted. Finally, this study was reported in accordance with the STROBE guidelines (Additional File 2).

\section{Results}

3.1. Sociodemographic Characteristics of the Participants. A total of 320 adults with visual impairments participants were included in this study. This is a $94.9 \%$ response rate and beyond the power calculated sample size $(n=306)$. The reasons for nonresponses were no time $(n=7)$, not interested and refusal to participate $(n=6)$, and incomplete medical review chart profile $(n=4)$. The age of the study 
participants ranged from 22 to 83 years with a mean age of $55.94 \pm 14.2$ years. The mean body mass indexes of the participants were $19.97 \mathrm{~kg} / \mathrm{m}^{2}( \pm 2.2)$. Nearly two-thirds of the participant $70.3 \%$ had a normal range of BMI (18.5 to 24.9). Nearly, one-third $(29,4 \%)$ of the participants were housewives, most of them reported their religious affiliation as orthodox Christians (90.3\%), and almost all of them (95.3\%) reported no smoking habits. The sociodemographic characteristics of the participants are presented in Table 1.

3.2. Vision-Related Characteristics of the Study Participants. Among the study participants, nearly half (46.6\%) of the participants were diagnosed with glaucoma, and more than one-third of adults had mild visual impairment (40.6\%) and moderate VI (40.3\%) based on Snell's E-chart reading. Table 2 shows the vision-related characteristics of adults with visual impairments.

\subsection{Fall-Related Injuries among Medically Diagnosed Adults} with Visual Impairments. The predictors and distribution of fall-related injuries among medically diagnosed adults with visual impairments are shown in Table 3. In this study, (24.7\%, 95\% CI: 20.0-29.4\%) people with visual impairment have sustained fall-related injuries. The higher fall-related injuries were noted among male participants (54.4\%) and older adults (45.6\%). Nearly, two-thirds (67.1\%) of adults who noted fall-related injuries were diagnosed with glaucoma followed by cataract $(26.6 \%)$. The types of fall-related injuries reported by the participants are shown in Figure 1.

3.4. Regression Analysis. In the univariate regression analyses, fall-related injuries were significantly associated with age, BMI, associated medical comorbidity, severity of VI, cause of VI, taking medication, family support, and depression. However, the multivariable analysis revealed that severity of visual impairment, cause of visual impairment, taking one or more medications, good family support, and having depression were significant predictors for fall-related injuries. Table 4 shows the association between sociodemographic variables, vision-related variables, behavioral variables, and medical-related variables with dependent variables among the study participants.

\section{Discussion}

The finding of this study reported that $24.7 \%$ with (95\% CI: 20.0-29.4\%) adults with visual impairments experienced one or more fall-related injuries. This shows that fall-related injuries are the main reason for hospital visits; and one of the main causes of disability among visually impaired adults, in addition to having a socioeconomic impact on an individual and on the development of the countries [7,9]. Among the study participants who have experienced fall-related injuries, $70.8 \%$ had soft tissue injuries which are bruising, skin damage, and abrasion, and $20.3 \%$ had reported fractures in different regions of the body. This finding is harmonized with the studies conducted in the USA [22]. The severity of visual impairment, cause of visual impairment, taking one or more medications, having family support, and having depression were significant predictors for fall-related injuries among visually impaired individuals.

The incidence of fall-related injures found in the current study is comparable with the results of the studies done in the United Kingdom 21\% [23] and Suburban, Australia 26\% [24]. However, the reported incidence of fall-related injuries in this study was found to be lower $(24.7 \%)$ compared to the studies done in Sydney, Australia 63\% [9]. The variation might be due to the difference in study participants; most of the study participants had been diagnosed with different eye disease including cataract, glaucoma, age-related maculopathy, diabetic retinopathy, uncorrected refractive error, and different other eye diseases, and most of the study participants were diagnosed with glaucoma (46.6\%). However, all of the study participants of the studies of Australia included only patients with age-related maculopathy [9]. Another possible reason could be the difference in study design and sample size variation; this study is conducted in a large sample size with an institutional-based cross-sectional study design while the study done in Sydney, Australia, used seventy-six community dwelling diagnosed with age-related macular degeneration with community-based study conducted.

However, the incidence rate of fall-related injuries reported in this study was found to be higher when compared to the study conducted in the USA $10 \%$ [6]. The possible reason for this discrepancy observed in the incidence rate of fall-related injuries could be due to the difference in the study area, study participants, sample size, and study settings. Furthermore, factors like differences in the educational level of the participants, availability of mobility aids, awareness program on risk factors and preventions, adjunct care in the eye clinic, and health-related facilities might also be the reasons for the lower incidence of fall-related injuries in these countries.

Another remarkable finding in the present study was the severity of VI, the cause of VI, taking medication, having family support, and depression as independent predictors of fall-related injuries with higher odds. Those participants diagnosed with a moderate level of VI were 2.91 times and a severe level of VI 3.58 times more likely to have fall-related injuries as compared to individuals who had mild VI (Table 4). This result was supported by other studies [24-26]. The adjusted odds of fall-related injuries were 10.63 times higher among adults diagnosed with cataract and 15.35 times higher among visual impairment adults diagnosed with diabetic retinopathy as compared to other eye diseases. This finding is supported by different studies. People with glaucoma and diabetic retinopathy can have compromised visual field which is associated with poor postural stability and a greater capacity to bump into objects, which could also lead to a greater tendency to fall and fall-related injury $[4,27]$.

Adult people with visual impairment who had associated depression comorbidity were 3.82 times more likely to have fall-related injuries as compared to their counterparts in this finding. Evidence that depression contributes to fall risk is 
Table 1: The sociodemographic characteristics of the study participants, Gondar, Ethiopia $(n=320)$.

\begin{tabular}{|c|c|c|c|}
\hline Variables & Categories & Frequency $(n)$ & Percent (\%) \\
\hline \multirow{3}{*}{ Age in years (mean age $((55.94 \pm 14.2))$} & $22-44$ & 79 & 24.6 \\
\hline & $45-64$ & 132 & 41.3 \\
\hline & Greater than 64 & 109 & 34.1 \\
\hline \multirow{2}{*}{ Sex } & Male & 187 & 58.4 \\
\hline & Female & 133 & 41.6 \\
\hline \multirow{3}{*}{ Residence } & Urban & 129 & 40.3 \\
\hline & Rural & 191 & 59.7 \\
\hline & Not married & 12 & 3.8 \\
\hline \multirow{3}{*}{ Marital status } & Married & 256 & 80.0 \\
\hline & Divorced & 29 & 9.1 \\
\hline & Windowed & 23 & 7.2 \\
\hline \multirow{3}{*}{ Religion } & Orthodox Christian & 289 & 90.3 \\
\hline & Protestant & 2 & 0.6 \\
\hline & Muslim & 29 & 9.1 \\
\hline \multirow{7}{*}{ Occupation } & Housewife & 94 & 29.4 \\
\hline & Farmer & 142 & 44.4 \\
\hline & Civil servant & 30 & 9.4 \\
\hline & Merchant & 31 & 9.7 \\
\hline & Unemployed & 7 & 2.2 \\
\hline & Retired & 15 & 4.7 \\
\hline & Student & 1 & 0.3 \\
\hline \multirow{5}{*}{ BMI $(\mathrm{kg} / \mathrm{m} 2)\left(\right.$ mean $19.97 \mathrm{~kg} / \mathrm{m}^{2}( \pm 2.2)$} & Underweight $(<18.5)$ & 82 & 25.6 \\
\hline & Normal (18.5-24.9) & 225 & 70.3 \\
\hline & Overweight (25-29.9) & 13 & 4.1 \\
\hline & Obese $(>29.9)$ & 0.0 & 0.0 \\
\hline & $<1000$ & 137 & 42.8 \\
\hline \multirow{3}{*}{ Income (ETB/month) } & $1000-2000$ & 99 & 30.9 \\
\hline & $2001-3000$ & 46 & 14.4 \\
\hline & $>3000$ & 38 & 11.9 \\
\hline \multirow{5}{*}{ Level of education } & No formal school & 189 & 59.1 \\
\hline & Primary school & 67 & 20.9 \\
\hline & Secondary school & 28 & 8.8 \\
\hline & Diploma & 17 & 5.3 \\
\hline & Degree and above & 19 & 5.9 \\
\hline \multirow{3}{*}{ Smoking habit } & Never & 305 & 95.3 \\
\hline & Past smoker & 5 & 1.6 \\
\hline & Current smoker & 10 & 3.1 \\
\hline \multirow{3}{*}{ Drinking alcohol habit } & Never & 194 & 60.6 \\
\hline & Past alcoholic & 37 & 11.6 \\
\hline & Current alcoholic & 89 & 27.8 \\
\hline \multirow{2}{*}{ Physical exercise } & No & 277 & 86.6 \\
\hline & Yes & 43 & 13.6 \\
\hline \multirow{2}{*}{ Taking medication } & No & 218 & 68.1 \\
\hline & Yes & 102 & 31.9 \\
\hline \multirow{5}{*}{ Types of medication $(n=102)$} & Antihypertensive & 25 & 24.5 \\
\hline & Psychotropic medication & 6 & 5.9 \\
\hline & Diabetic medication & 19 & 18.6 \\
\hline & Medication for different eye diseases & 41 & 40.2 \\
\hline & Unspecified & 11 & 10.8 \\
\hline \multirow{3}{*}{ Number of medications/day $(N=102)$} & One & 76 & 74.5 \\
\hline & Two & 19 & 18.6 \\
\hline & Three and more & 7 & 6.9 \\
\hline
\end{tabular}

consistent with the documented association between depression and disability and depressive symptoms were associated with a twofold risk of an adverse fall event and unintentional injuries during the patient's episode of care $[7,28]$. On the other hand, $87.5 \%$ of adults with visual impairment who had good family/social support are less likely to have fall-related injuries than counterparts of those not having social or family support.

This study also showed that taking medication was also found to be one of the predictors of fall-related injuries among medically diagnosed visually impaired adults in this study. The odds of having falls were 6.35 times higher among 
TABLE. 2: Vision-related characteristics of the study participant in Gondar, Ethiopia $(n=320)$.

\begin{tabular}{lccc}
\hline Variables & Categories & Frequency $(n)$ & 34 \\
& Cataract & 149 & Percent $(\%)$ \\
\hline & Glaucoma & 22 & 46.6 \\
Cause of visual impairment & ARM & 12 & 6.9 \\
& Diabetic retinopathy & 43 & 3.8 \\
& URE & 60 & 13.4 \\
Severity of visual impairment & Other eye diseases & 130 & 40.6 \\
& Mild visual impairment & 129 & 40.3 \\
\hline
\end{tabular}

ARM : age-related maculopathy, URE: uncorrected refractive error.

TABLE 3: Fall-related injuries among medically diagnosed adults with visual impairments, Gondar, Ethiopia $(n=320)$.

\begin{tabular}{|c|c|c|c|c|c|}
\hline \multirow{2}{*}{ Variables } & \multirow{2}{*}{ Categories } & \multicolumn{4}{|c|}{ Fall-related injury } \\
\hline & & No $(\%)$ & Yes $(\%)$ & $x^{2}$ & $P$ \\
\hline \multirow{3}{*}{ Age in years (mean age $((55.94 \pm 14.2))$} & $22-44$ & $65(82.3)$ & $14(17.7)$ & \multirow{3}{*}{6.64} & \multirow{3}{*}{0.35} \\
\hline & $45-64$ & $103(78.0)$ & $29(22.0)$ & & \\
\hline & Greater than 64 & $73(67.0)$ & $36(33.0)$ & & \\
\hline \multirow{2}{*}{ Sex } & Male & $144(77.0)$ & $43(23.0)$ & \multirow{2}{*}{0.69} & \multirow{2}{*}{0.41} \\
\hline & Female & $97(72.9)$ & $36(27.1)$ & & \\
\hline \multirow{2}{*}{ Residence } & Urban & $91(70.5)$ & $38(29.5)$ & \multirow[b]{2}{*}{2.65} & \multirow{2}{*}{0.10} \\
\hline & Rural & $150(78.5)$ & $41(21.5)$ & & \\
\hline \multirow{4}{*}{ Marital status } & Not married & $9(75.0)$ & $3(25.0)$ & \multirow{4}{*}{17.6} & \multirow{4}{*}{0.001} \\
\hline & Married & $201(78.5)$ & $55(21.5)$ & & \\
\hline & Divorced & $22(75.9)$ & $7(24.1)$ & & \\
\hline & Windowed & $9(39.1)$ & $14(60.9)$ & & \\
\hline \multirow{3}{*}{ Religion } & Orthodox Christian & $220(76.1)$ & $69(23.9)$ & \multirow{3}{*}{2.25} & \multirow{3}{*}{0.32} \\
\hline & Protestant & $2(100.0)$ & $0(0.00)$ & & \\
\hline & Muslim & $19(65.5)$ & $10(34.5)$ & & \\
\hline \multirow{7}{*}{ Occupation } & Housewife & $67(71.3)$ & $27(28.7)$ & \multirow{7}{*}{15.97} & \multirow{7}{*}{0.01} \\
\hline & Farmer & $114(80.3)$ & $28(19.7)$ & & \\
\hline & Civil servant & $27(90.0)$ & $3(10.0)$ & & \\
\hline & Merchant & $16(51.6)$ & $15(48.4)$ & & \\
\hline & Unemployed & $5(71.4)$ & $2(28.6)$ & & \\
\hline & Retired & $11(73.3)$ & $4(26.7)$ & & \\
\hline & Student & $1(100.0)$ & $0(0.00)$ & & \\
\hline \multirow{4}{*}{ BMI $\left(\mathrm{kg} / \mathrm{m}^{2}\right)\left(\right.$ mean $19.97 \mathrm{~kg} / \mathrm{m}^{2}( \pm 2.2)$} & Underweight $(<18.5)$ & $57(69.5)$ & $25(30.5)$ & \multirow{3}{*}{6.07} & \multirow{3}{*}{0.48} \\
\hline & Normal (18.5-24.9) & $177(78.7)$ & $48(21.3)$ & & \\
\hline & Overweight (25-29.9) & $7(53.8)$ & $6(46.2)$ & & \\
\hline & $<1000$ & $102(74.5)$ & $35(25.5)$ & & \\
\hline & $1000-2000$ & $74(74.7)$ & $25(25.3)$ & & \\
\hline Income (ETB/month) & $2001-3000$ & $37(80.4)$ & $9(19.6)$ & 0.77 & 0.86 \\
\hline & $>3000$ & $28(73.7)$ & $10(26.3)$ & & \\
\hline & Cataract & $13(38.2)$ & $21(61.8)$ & & \\
\hline & Glaucoma & $116(77.9)$ & $53(22.1)$ & & \\
\hline & ARM & $15(68.2)$ & $7(31.8)$ & 57.35 & 0.001 \\
\hline Cause of visual impairment & Diabetic retinopathy & $3(25.0)$ & $9(75.0)$ & & \\
\hline & Uncorrected refractive error & $41(95.3)$ & $2(4.7)$ & & \\
\hline & Other eye diseases & $53(88.3)$ & $7(11.7)$ & & \\
\hline & Mild & $117(90.0)$ & $13(10.0)$ & & \\
\hline Severity of visual impairment & Moderate & $93(72.1)$ & $36(27.9)$ & 35.48 & 0.001 \\
\hline & Severe & $31(50.8)$ & $30(49.2)$ & & \\
\hline & Never & $23(75.7)$ & $74(24.3)$ & & \\
\hline Smoking habit & Past smoker & $2(40.0)$ & $3(60.0)$ & 3.5 & 0.17 \\
\hline & Current smoker & $8(80.0)$ & $2(20.0)$ & & \\
\hline & Never & $138(71.1)$ & $56(28.9)$ & & \\
\hline Drinking alcohol habit & Past alcoholic & $28(75.7)$ & $9(24.3)$ & 5.67 & 0.05 \\
\hline & Current alcoholic & $75(84.3)$ & $14(15.7)$ & & \\
\hline
\end{tabular}


TABle 3: Continued.

\begin{tabular}{|c|c|c|c|c|c|}
\hline \multirow{2}{*}{ Variables } & \multirow{2}{*}{ Categories } & \multicolumn{4}{|c|}{ Fall-related injury } \\
\hline & & No $(\%)$ & Yes $(\%)$ & $x^{2}$ & $P$ \\
\hline \multirow{2}{*}{ Taking medication } & No & $190(87.2)$ & $28(12.8)$ & \multirow{2}{*}{51.6} & \multirow{2}{*}{0.001} \\
\hline & Yes & $51(50.0)$ & $51(50.0)$ & & \\
\hline \multirow{2}{*}{ Physical exercise } & No & $206(74.4)$ & $71(25.6)$ & \multirow{2}{*}{0.99} & \multirow{2}{*}{0.32} \\
\hline & Yes & $35(81.4)$ & $8(18.6)$ & & \\
\hline \multirow{2}{*}{ Level of mobility } & Independent without mobility aid & $212(81.2)$ & $49(18.8)$ & \multirow{2}{*}{28.04} & \multirow{2}{*}{0.001} \\
\hline & Independent with mobility aid & $29(48.3)$ & $30(51.7)$ & & \\
\hline \multirow{2}{*}{ Family/social support } & No & $82(66.7)$ & $41(33.3)$ & \multirow{2}{*}{8.03} & \multirow{2}{*}{0.005} \\
\hline & Yes & $159(80.7)$ & $38(19.3)$ & & \\
\hline \multirow{2}{*}{ Medical comorbidity } & No & $173(84.0)$ & $33(16.0)$ & \multirow{2}{*}{23.36} & \multirow{2}{*}{0.001} \\
\hline & Yes & $68(59.6)$ & $46(40.4)$ & & \\
\hline \multirow{2}{*}{ Poor urine control } & No & $235(75.8)$ & $75(24.2)$ & \multirow{2}{*}{1.3} & \multirow{2}{*}{0.25} \\
\hline & Yes & $6(60.0)$ & $4(40.0)$ & & \\
\hline
\end{tabular}

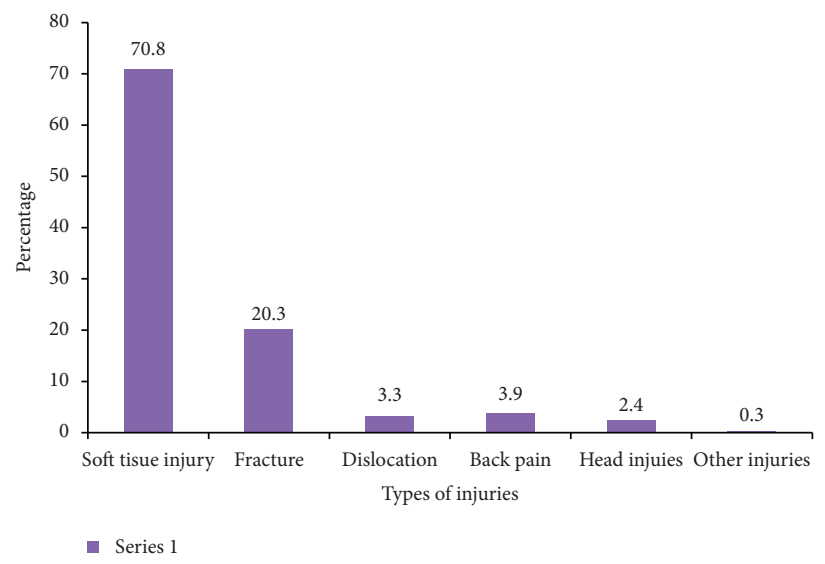

FIGURE 1: Types of fall-related injuries reported by adults with visual impairment in Gondar, Ethiopia $(n=79)$.

TABLE 4: Factors associated with fall-related injuries in adults with medically diagnosed visual impairment at Gondar, Ethiopia $(n=320)$.

\begin{tabular}{|c|c|c|c|c|c|}
\hline Variables & Categories & Univariate COR $(95 \% \mathrm{CI})$ & $P$ value & Multivariate AOR (95\%CI) & $P$ value \\
\hline \multirow{3}{*}{ Age in year } & $22-44$ & Ref. & - & Ref. & - \\
\hline & $45-64$ & $1.31(0.64-2.66)$ & 0.46 & $0.58(0.20-1.63)$ & 0.30 \\
\hline & $>64$ & $2.29(1.14-4.62)^{*}$ & 0.02 & $0.52(0.18-1.55)$ & 0.24 \\
\hline \multirow{3}{*}{ BMI $\left(\mathrm{kg} / \mathrm{m}^{2}\right)$} & Underweight $(<18.5)$ & Ref. & - & Ref. & - \\
\hline & Normal (18.5-24.9) & $0.62(0.35-1.09)^{*}$ & 0.09 & $0.78(0.37-1.64)$ & 0.50 \\
\hline & Overweight (25-29.9) & $1.95(0.59-6.41)$ & 0.27 & $1.10(0.24-5.14)$ & 0.89 \\
\hline \multirow{6}{*}{ Cause of VI } & Cataract & $12.23(4.28-34.9)^{*}$ & 0.001 & $10.63(2.49-45.26)^{*}$ & 0.001 \\
\hline & Glaucoma & $2.15(0.89-5.18)^{*}$ & 0.09 & $2,51(0.78-8.13)$ & 0.12 \\
\hline & ARM & $3,53(1.07-11.66)^{*}$ & 0.03 & $3.4(0.69-16.84)$ & 0.13 \\
\hline & Diabetic retinopathy & $22.7(4.93-104.47)^{*}$ & 0.001 & $15.35(2.51-93.96)^{*}$ & 0.001 \\
\hline & Uncorrected refractive error & $0.36(0.07-1.87)$ & 0.22 & $0.92(0.15-5.49)$ & 0.93 \\
\hline & Other eye diseases & Ref. & - & Ref. & - \\
\hline \multirow{3}{*}{ Severity of VI } & Mild & Ref. & - & Ref. & - \\
\hline & Moderate & $3.48(1.75-6.95)^{*}$ & 0.001 & $2.91(1.23-6.87)^{*}$ & 0.01 \\
\hline & Sever & $8.71(4.07-18.66)^{*}$ & 0.001 & $3.58(1.26-10.17)^{*}$ & 0.02 \\
\hline \multirow{2}{*}{ Medical comorbidity } & No & Ref. & - & Ref. & - \\
\hline & Yes & $3.55(2.09-6.01)^{*}$ & 0.001 & $1.21(0.57-2.57)$ & 0.62 \\
\hline \multirow{2}{*}{ Taking medication } & No & Ref. & - & Ref. & - \\
\hline & Yes & $7.14(4.09-12.47)^{*}$ & 0.001 & $6.35(2.93-13.75)^{*}$ & 0.001 \\
\hline \multirow{2}{*}{ Family support } & No & $2.09(1.25-3.50)^{*}$ & 0.005 & $2.13(1.08-4.19)^{*}$ & 0.03 \\
\hline & Yes & Ref. & - & Ref. & - \\
\hline \multirow{2}{*}{ Depression } & No & Ref. & - & Ref. & - \\
\hline & Yes & $3.74(1.52-9.17)^{*}$ & 0.004 & $3.82(1.27-11.45)^{*}$ & 0.02 \\
\hline
\end{tabular}

*Statically significant variables with $P$ value $<0.05$; ref.: reference category; COR: crude odds ratio; AOR: adjusted odds ratio; CI: confidence interval; and VI: visual impairment. 
people who had taken one or more medications as compared to those individuals not taking medication. This finding was supported by different studies, which found that visually impaired people who had to take greater than three medications for different comorbidity were two times more likely to experience fall and fall-related injuries than counterparts. Different studies found that the total number of medications dispensed to the patient was significantly associated with fall and related injuries among older adults. This is due to the adverse effect of the medication, drug-drug interaction, and the metabolic effect of the drug on the body. Sedatives, antipsychotics, and sedating antidepressants cause drowsiness and slow reaction times. Some antidepressants and antipsychotics also cause orthostatic hypotension [22, 29]. The possible explanation might be medication use is a factor associated with falls and injuries in older adults. Polypharmacy, particularly the use of four or more medications, increases the risk of falling and related injuries [29]. Additionally, the use of certain classes of medications, including sedatives, hypnotics, antipsychotics, antidepressants, and antiarrhythmics, has demonstrated an increased association with falls $[30,31]$. Although the use of medications may predispose VI older adults to falls and related injuries, medications may also cause changes in vision or vision loss, another risk factor for fall-related injuries in older adults $[18,32]$. Many medications can lead to an ocular adverse event [33, 34]. Drugs that possess anticholinergic properties, such as antihistamines, antipsychotics, and tricyclic antidepressants, are associated with visual disturbances including blurred vision, diplopia (double vision), and cycloplegia (loss of accommodation). Amiodarone is a commonly used antiarrhythmic agent that can cause dose-dependent corneal deposits that may lead to lens opacities and halo vision.

\section{The Strength and Limitation of the Study}

The possible strength of this study was the inclusiveness of different types of study participants which were adults diagnosed with different types of eye disease; and all the measurements were undergone by ophthalmic nurses professional in order to exclude measurement bias. For the benefits of future research, there are some notable limitations, these fall-related injuries were self-reported and reviewed from patient's medical registration and identification charts. Another possible limitation, the cross-sectional nature of these studies, presents limitations in terms of casual association interpretation and not showing cause and effect.

\section{Conclusion}

Soft tissue injuries were the most common fall-related injuries reported by the study participants followed by fractures. Fall-related injuries were the main reason for hospital visits among adults with visual impairments. The severity of visual impairment, the cause of visual impairment, taking one or more medications, having family support, and having depression were significant predictors for fall-related injuries.
Abbreviations
AOR: Adjusted odds ratio
ARM: Age-related maculopathy
BMI: Body mass index
CI: $\quad$ Confidence interval
COR: Crude odds ratio
LMICs: Low- and middle-income countries
SD: $\quad$ Standard deviation
USA: United State of America
URE: Uncorrected refractive error
VI: Visual impairment.

\section{Data Availability}

All data relevant to our findings are contained within the article. Further details on the dataset and queries will be made available upon reasonable request to the corresponding author (mogesgashaw1@gmail.com).

\section{Ethical Approval}

Ethical clearance was obtained from the ethical review committee of the University of Gondar, College of Medicine and Health Sciences, from the school of medicine.

\section{Consent}

After informing the purpose, benefits, risks, confidentiality of the information, and voluntary nature of participants in the study, consent was obtained from each of the participants. For participants with severe visual impairment and who were illiterate, the consent form was read for them. Name and personal identifiers were not included in the questionnaire. Participants' involvements in the study were on a voluntary basis and respondents were informed to refuse or stop at any point during the interview.

\section{Disclosure}

The views presented in the article are those of the authors and do not necessarily express the views of the funding organization. The University of Gondar was not involved in the design of the study, data collection, analysis, and interpretation.

\section{Conflicts of Interest}

All authors declare that they have no conflicts of interest resulting from this work, not in financial or personal relationships.

\section{Acknowledgments}

The authors are grateful to the University of Gondar for funding. The author's gratitude and appreciation go to the 
data collectors and the study participants. This study was funded by the University of Gondar.

\section{Supplementary Materials}

Additional File 1: English version questionnaire. Additional File 2: STROBE statement checklist. (Supplementary Materials)

\section{References}

[1] S. R. Salomão, M. R. K. H. Mitsuhiro, and R. Belfort Jr., "Visual impairment and blindness: an overview of prevalence and causes in Brazil," Anais da Academia Brasileira de Ciências, vol. 81, no. 3, pp. 539-549, 2009.

[2] World Health Organization, Media Centre Vision Impairment and BlindnessWorld Health Organization, Geneva, Switzerland, 2017.

[3] L. Bezabih, T. Workineh, and R. Olana, "Prevalence and factors associated with childhood visual impairment in Ethiopia," Clinical Ophthalmology, vol. 11, p. 1941, 2017.

[4] F. B Daga, A. Diniz-Filho, E. R. Boer, C. P. Gracitelli, R. Y. Abe, and M. Fajpo, Fear of falling and postural reactivity in patients with glaucoma," PLoS One, vol. 12, no. 12, ., Article ID e0187220, 2017.

[5] J. S. Williams, P. Kowal, H. Hestekin et al., "Prevalence, risk factors and disability associated with fall-related injury in older adults in low-and middle-incomecountries: results from the WHO Study on global AGEing and adult health (SAGE)," BMC Medicine, vol. 13, no. 1, p. 147, 2015.

[6] C. M. Patino, R. McKean-Cowdin, S. P. Azen et al., "Central and peripheral visual impairment and the risk of falls and falls with injury," Ophthalmology, vol. 117, no. 2, pp. 199-206, 2010.

[7] A. Dhital, T. Pey, and M. R. Stanford, "Visual loss and falls: a review," Eye, vol. 24, no. 9, p. 1437, 2010.

[8] X.-Y. Zhang, J. Shuai, and L.-P. Li, "Vision and relevant risk factor interventions for preventing falls among older people: a network meta-analysis," Scientific Reports, vol. 5, p. 10559, 2015.

[9] J. M. Wood, P. Lacherez, A. A. Black, M. H. Cole, M. Y. Boon, and G. K. Kerr, "Risk of falls, injurious falls, and other injuries resulting from visual impairment among older adults with age-related macular degeneration," Investigative Opthalmology \& Visual Science, vol. 52, no. 8, pp. 5088-5092, 2011.

[10] M. Gashaw, B. Janakiraman, A. Minyihun, G. Jember, and K. Sany, "Self-reported fall and associated factors among adult people with visual impairment in Gondar, Ethiopia: a crosssectional study," BMC Public Health, vol. 20, pp. 1-10, 2020.

[11] L. A. Talbot, R. J. Musiol, E. K. Witham, and M. Ejjbph, "Falls in young, middle-aged and older community dwelling adults: perceived cause," Environmental Factors and Injury, vol. 5, no. 1, p. 86, 2005.

[12] S. K. Verma, J. L. Willetts, H. L. Corns, H. R. MarucciWellman, D. A. Lombardi, and C. Tkjpo, "Falls and fall-related injuries among community-dwelling adults in the United States," PLoS One, vol. 11, no. 3, Article ID e0150939, 2016.

[13] S. Pattaramongkolrit, S. Sindhu, O. Thosigha, and W. Somboontanot, "Fall-related factors among older," Visually-impaired Thais, vol. 17, no. 2, pp. 181-196, 2013.

[14] R. Legood, P. Scuffham, and C. Cryer, "Are we blind to injuries in the visually impaired? A review of the literature," Injury Prevention, vol. 8, no. 2, pp. 155-160, 2002.
[15] Z. T. Tessema and Y. Animut, "Spatial distribution and determinants of an optimal ANC visit among pregnant women in Ethiopia: further analysis of 2016 Ethiopia demographic health survey," BMC Pregnancy and Childbirth, vol. 20, no. 1, pp. 1-13, 2020.

[16] V. Kasiulevičius, V. Šapoka, and R. Filipavičiūtè, "Sample size calculation in epidemiological studies," Gerontologija, vol. 7, no. 4, pp. 225-231, 2006.

[17] L. Dandona and R. Dandona, "Revision of visual impairment definitions in the international statistical classification of diseases," BMC Medicine, vol. 4, p. 7, 2006.

[18] S. R. Lord and J. Dayhew, "Visual risk factors for falls in older people," Journal of the American Geriatrics Society, vol. 49, no. 5, pp. 508-515, 2001.

[19] R. Q. Ivers, R. Norton, R. G. Cumming, M. Butler, and A. J. Campbell, "Visual impairment and hip fracture," American Journal of Epidemiology, vol. 152, no. 7, pp. 633639, 2000.

[20] F. Melton and M. Horvat, "Intrinsic and functional components of falls risk in older adults with visual impairments," Insight: Research and Practice in Visual Impairment and Blindness, vol. 4, no. 2, 2011.

[21] L. R. F. Mata, C. Azevedo, A. G. Policarpo, and M. JTJRl-ade, "Factors associated with the risk of fall in adults in the postoperative period: a cross-sectional study," Revista LatinoAmericana de Enfermagem, vol. 25, 2017.

[22] R. J. Reed-Jones, G. R. Solis, K. A. Lawson, A. M. Loya, D. Cude-Islas, and C. S. Berger, "Vision and falls: a multidisciplinary review of the contributions of visual impairment to falls among older adults," Maturitas, vol. 75, no. 1, pp. 22-28, 2013.

[23] P. A. Scuffham, R. Legood, E. C. F. Wilson, and T. KennedyMartin, "The incidence and cost of injurious falls associated with visual impairment in the UK," Visual Impairment Research, vol. 4, no. 1, pp. 1-14, 2002.

[24] T. Hong, P. Mitchell, G. Burlutsky, C. Samarawickrama, and J. J. Wang, "Visual impairment and the incidence of falls and fractures among older people: longitudinal findings from the Blue Mountains Eye Study," Investigative Opthalmology \& Visual Science, vol. 55, no. 11, pp. 7589-7593, 2014.

[25] B. E. K. Klein, R. Klein, K. E. Lee, and K. J. Cruickshanks, "Performance-based and self-assessed measures of visual function as related to history of falls, hip fractures, and measured gait time," Ophthalmology, vol. 105, no. 1, pp. 160-164, 1998.

[26] A. L. Coleman, K. Stone, S. K. Ewing et al., "Higher risk of multiple falls among elderly women who lose visual acuity," Ophthalmology, vol. 111, no. 5, pp. 857-862, 2004.

[27] K. A. Turano, A. T. Broman, K. Bandeen-Roche et al., "Association of visual field loss and mobility performance in older adults: salisbury Eye Evaluation Study," Optometry and Vision Science, vol. 81, no. 5, pp. 298-307, 2004.

[28] A. L. Byers, T. Sheeran, A. E. Mlodzianowski, B. S. Meyers, P. Nassisi, and M. L. Bruce, "Depression and risk for adverse falls in older home health care patients," Research in Gerontological Nursing, vol. 1, no. 4, pp. 245-251, 2008.

[29] V. Milos, B. Å, M. Magnusson, U. Jakobsson, T. Westerlund, and P. Midlöv, "Fall risk-increasing drugs and falls: a crosssectional study among elderly patients in primary care," BMC Geriatrics, vol. 14, no. 1, p. 40, 2014.

[30] J. C. Woolcott, K. J. Richardson, M. O. Wiens et al., "Metaanalysis of the impact of 9 medication classes on falls in elderly persons," Archives of Internal Medicine, vol. 169, no. 21, pp. 1952-1960, 2009. 
[31] R. M. Leipzig, R. G. Cumming, and M. E. Tinetti, "Drugs and falls in older people: a systematic review and meta-analysis: I. Psychotropic drugs," Journal of the American Geriatrics Society, vol. 47, no. 1, pp. 30-39, 1999.

[32] A. J. Campbell, M. C. Robertson, S. J. L. Grow et al., "Randomised controlled trial of prevention of falls in people aged $\geq 75$ with severe visual impairment: the VIP trial," $B M J$, vol. 331, no. 7520, p. 817, 2005.

[33] Y. Kaakeh and S. Abel, "Visual disturbances," Drug-induced Diseasespp. 250-274, American Society of Health-System Pharmacists, Bethesda, MD, USA, 2nd edition, 2010.

[34] R. M. Santaella and F. W. Fraunfelder, "Ocular adverse effects associated with systemic medications," Drugs, vol. 67, no. 1, pp. 75-93, 2007. 